
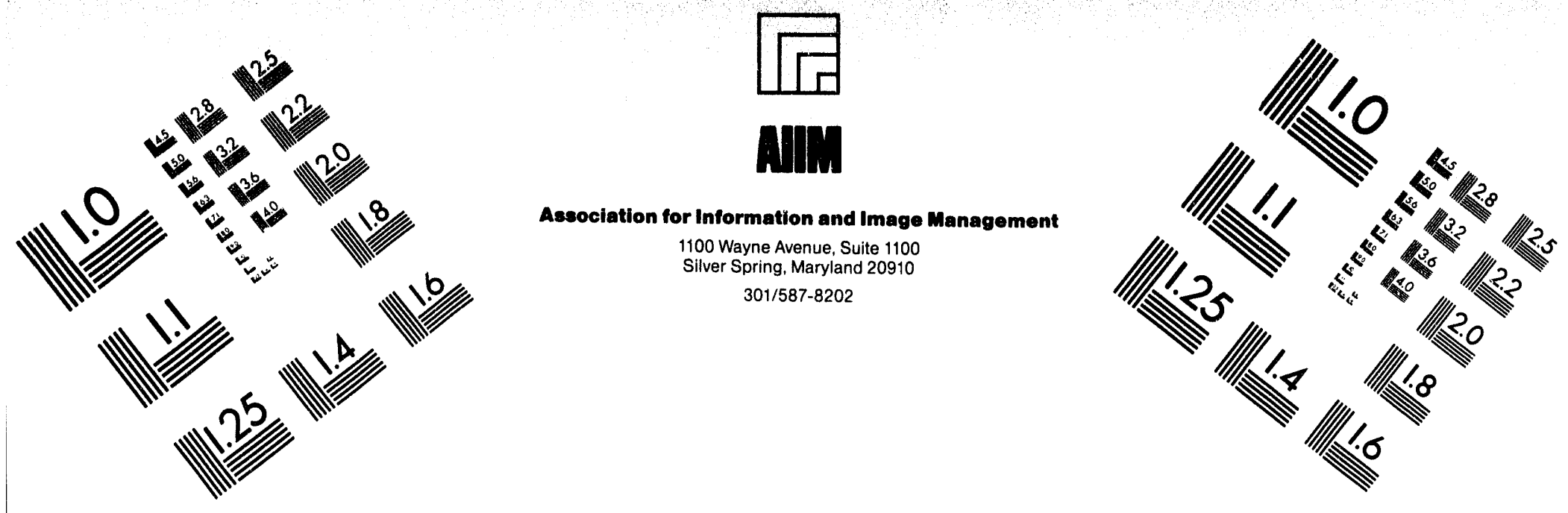

\title{
Centimeter
}

2
1

Inches
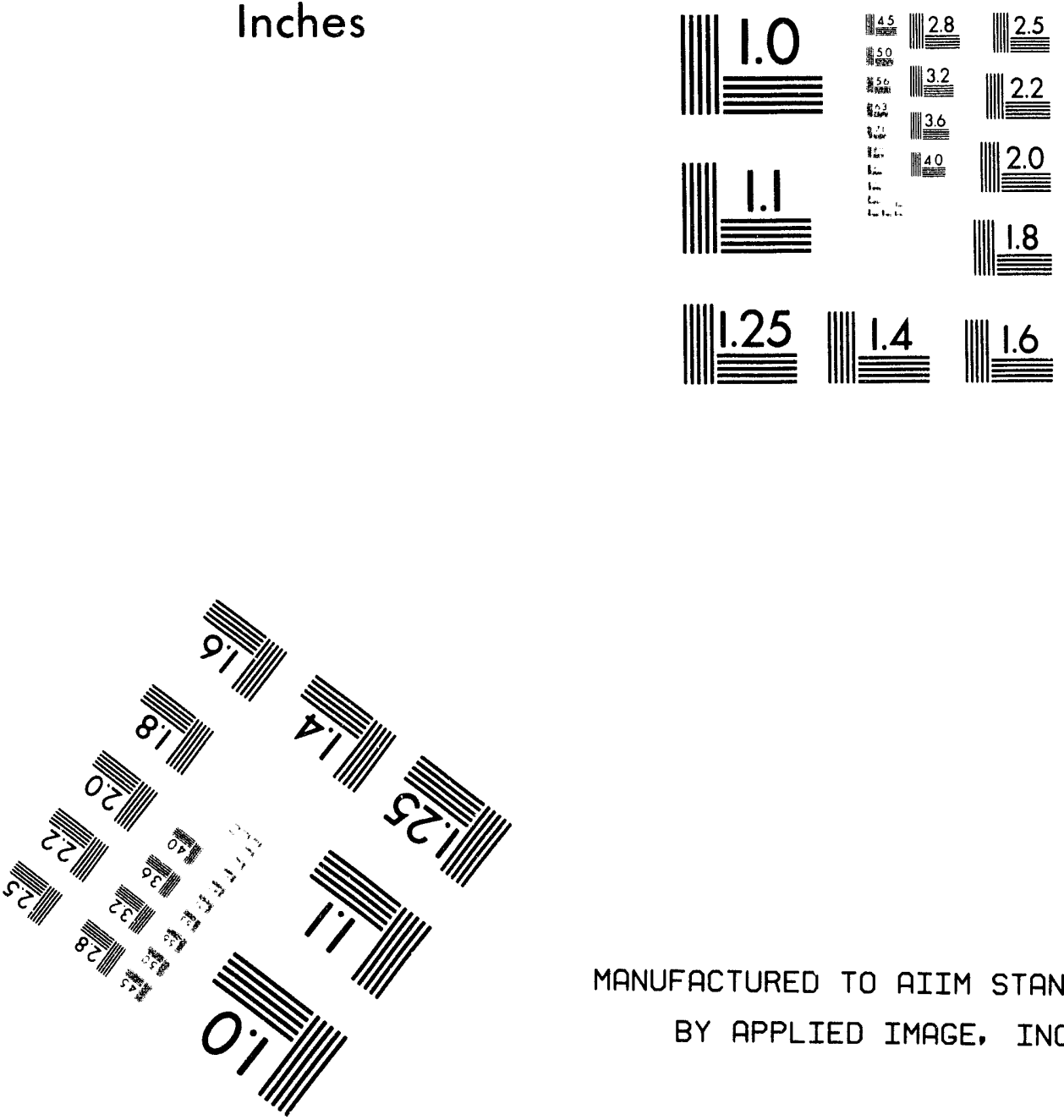

MANUFACTURED TO AIIM STANDARDS

BY APPLIED IMAGE, INC.

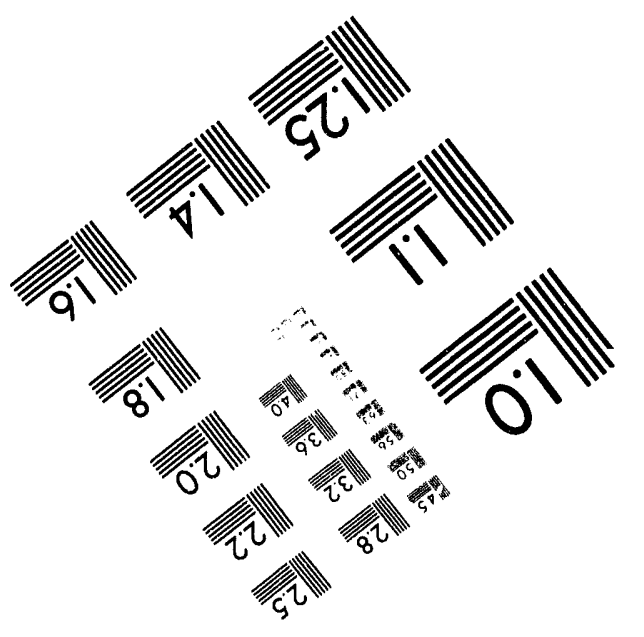



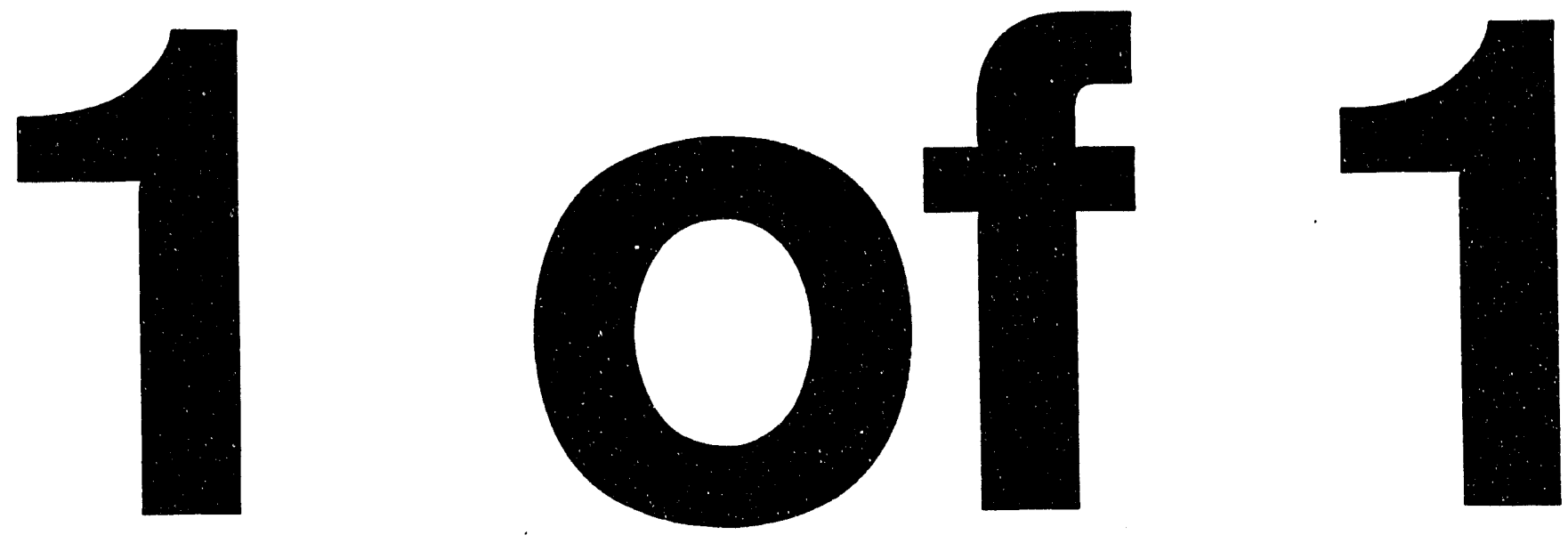


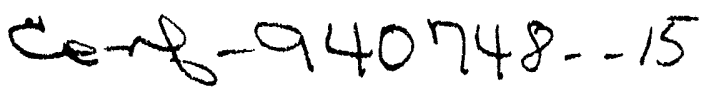

WSRC-MS-94-0113

\section{ANALYSIS OF CENSORED DATA IN GROUNDWATER MONITORING WELLS AT THE SAVANNAH RIVER SITE}

by

Weber, J.H.

Westinghouse Savannah River Company

Savannah Fiver Site

Aiken, South Carolina 29808

A document prepared for INTERNATIONAL NUCLEAR MATERIALS MANAGEMENT (INMM) ANNUAL MEETING 1994 at Naples, FL (USA) from 17 Jul -20 Jul 1994.

DOE Contract No. DE-AC09-89SR18035

This paper was prepared in connection with work done under the above contract number with the U. S.

Department of Energy. By acceptance of this paper, the publisher and/or recipient acknowledges the U. S. Government's right to retain a nonexclusive, royalty-free license in and to any copyright covering this paper, along with the right to reproduce and to authorize others to reproduce all or part of the copyrighted paper. 


\section{DISCLAIMER}

This report was prepared as an account of work sponsored by an agency of the United States Government. Neither the United States Government nor any agency thereof, nor any of their employees, makes any warranty, express or implied. or assumes any legal liability or responsibility for the accuracy. completeness, or usefulaess of any information. apparatus, product, or process disclosed, or represents that its use would not infringe privately owned rights. Reference herein to any specific commercial product. process, or service by trade name. trademark. manufacturer, or otherwise does not necessarily constitute or imply its endorsement, recommendation, or favoring by the United States Government or any agency thereof. The views, and opinions of authors expressed berein do not necessarily state or reflect those of the United States Government or any agency ithereof.

This report bas been reproduced directly from the best available copy.

Available to DOE and DOE contractors from the Office of Scieatific and Technical Information. P. O. Box 62, Oak Ridge. TN 37831: prices available from (615) $576-8401$.

Available to the public from the National Tecbnical Information Service. U. S. Deparmeat of Commerce. S285 Port Royal Rd.. Springfield. VA 22161 


\title{
ANALYSIS OF CENSORED DATA IN GROUNDWATER MONITORING WELLS AT THE SAVANNAH RIVER SITE
}

\author{
J.H. Weber Savannah River Technclogy Center, Applied Statistics Group, Aiken, S. C. 29802 USA \\ 803/725-5528
}

\section{ABSTRACT}

It is common in environmental analyses to deal with censored data. Censored data characteristically arise through laboratory analysis of samples with contaminant concentrations less than what the analytical method is able to reliably detect. These data are called "less than detectablen. Comparisons between downgradient or monitoring groundwater wells and upgradient or background wells are frequently done to determine if downgradient wells are more contaminated than background or some established maximum concentration limits (MCL's). In addition, parameter estimates are often desired. The presence of censored data complicates the statistics that can be used as estimators for individual populations or to estimate differences between two populations.

This paper describes the current process at Savannah River Site (SRS) to determine constituents of concern (COC's) for complying with groundwater monitoring and clean-up regulations. COC's are analytes found in downgradient monitoring wells in concentrations significantly greater than in background wells or significantly greater than the MCL's. Both parametric and non-parametric statistics are explored. Data plots are examined for outliers, trends, laboratory or sampling contamination, and unusually large detection limits for censored results. Wells are grouped by similar concentration levels to form a "characteristic" well, improving the estimation and decision process. Different methods are compared.

\section{INTRODUCTION}

This paper will describe the statistical analyses currently being used at SRS to develop COC lists and estimate concentration levels in the groundwater monitoring (POC) and background (BG) wells. Several parametric and non-parametric methodologies to determine a COC list are compared with the current SRS method.

For many regulatory purposes, statistical analyses of censored (less than detectable) ground water monitoring data are required to demonstrate presence or absence of statistically significant concentration levels in monitoring wells compared with background or established maximum concentration limits (MCL's), or to determine if there is a significant health risk. One of the requirements is to develop a list of constituents of concern (COC). In addition, parameter estimates of the ground water concentration levels are often desired.

The presence of results reported at "less than detection limits" adds a complex element to the statistical analyses. The actual concentration values for these "less than detected" results are generally unavailable. In addition, the data usually contain multiple detection limits due to (1) improvement in analytical methods over time, (2) use of alternate methods with higher Jetection limits, (3) several laboratories analyzing the samples, or (4) matrix characteristics and sample dilution factors used by the different laboratories and analytical methods. Thus, measurements above detection are often interspersed with results reported at less than detection.

Before analyzing any of the ground water data, plots of individual results over time, by well, laboratory, and analytical method are made $f o r$ each constituent with at least one result above detection limits. These plots are examined to determine if there are individual outliers, sampling, laboratory, or analytical priblerrs. Past experience has indicated that some methods produc: results with much smaller detection limits than other analytical methods. In addition, laboratory problems have been noted with a given laboratory for one or more quarters due to blank contamination, spiking of ground water samples, and significantly larger or smaller percent return than expected on the spiked quality control samples. If causes for these grouped outliers can be identified, these results are omitted from further analyses. Individual outlier results that appear not to conform to both preceding and succeeding results or that appear significantly different from replicate results either by the same laboratory or by different laboratories for the same quarter are flagged and investigated. If no cause for omitting the flagged outliers can be identified, a statistical outlier test is applied. Those results failing the outlier test at an alpha level of 0.005 are omitted from further analyses. The remaining data are again plotted to determine if there is a trend over time. The statistical analyses described in this paper 
assume all outliers and results reported with large detection limits have been omitted, and there is no significant trend over time. Large detection limits are limits that when divided by two exceed all observed results over all wells.

After the data qualification process, all constituents for which there are no results above detection in any of the monitoring wells are deleted from further consideration. Typically, results are reported for around 350 constituents, but after removing those with no results above detection, about 100 constituents remain for consideration. The list of potential COC's are further pared down by elimination of indicator parameters such as $\mathrm{pH}$, turbidity, total organic halogens, color, odor, specific conductance, etc. This generally reduces the number of constituents to be considered to less than 90 .

\section{DETERMINING QUARTER AVERAGES}

Since contract laboratories are required to make replicate analyses and split samples are required to be sent to two or more independent laboratories for analysis, not all results are independent. Results reported from the same sample and replicate laboratory and method results within the same quarter were averaged using the following procedure.

(1) All replicate results using the same method within the sume iaboratory, quarter, well, and constituent are averaged for a method mean. If $50 \%$ or more of the individual replicate results are above detection, the method mean is defined as above detection.

(2) The method means from (1) within the same laboratory, quarter, well, and constituent are averaged for a laboratory mean. If $50 \%$ or more of the method means are above detection, the laboratory mean is defined as above detection.

(3) The laboratory means from (2) within quarter, well, and constituent are averaged to get a quarter mean within well and constituent. If $50 \%$ or more of the laboratory means are above detection, then the quarter mean is defined as above detection.

The resulting quarter averages are considered to be independent. Before computing the quarter averages, results reported at less than detection are replaced by half the detection limit.

\section{DETERMINATION OF "CHARACTERISTIC" WELL}

Before comparing POC with BG wells, a characteristic "worst case" well is defined for each constituent and aquifer. The well with the largest average concentration and all other wells with a similar average concentration and variability are included in the "characteristic" well. If too many wells are included, the average concentration is diluted (underestimated) and there is an increase in the variability which decreases the sensitivity or power of the POC versus $B G$ comparison.

The following steps describe the procedure used to determine which wells are included in the "characteristic" well.

(1) If no well within the aquifer has at least $50 \%$ of the quarter mieans above detection, then all available wells are included in the characteristic well and steps 2 through 4 are omitted.

(2) If there are at least two wells with at least $50 \%$ of the results above detection, Levene's test for equality of variances is done. If Levene's test indicates no significant differences in variance estimates, then the variance estimates are pooled. If there are differences, then the two wells with the largest average concentrations are compared using a two sample t-test with unequal variances. If there are significant differences at an alpha level of 0.05 , then only the well with the largest mean concentration is included in the characteristic well; otherwise, the two wells with the largest average concentrations are included.

(3) All wells with less than $50 \%$ above detection are grouped together and the mean concentration computed. The one "less than $50 \%$ " mean concentration is then compared with the quarter results from wells with $50 \%$ or more above detection using analysis of variance (ANOVA). If the F-test of the ratio of the between well mean square error (BMSE) to the within well mean square error (WMSE) indicates no significant difference at the 0.05 level, then all wells are included in the characteristic well.

(4) If the F-test indicates there are differences, then the Tukey-Kramer pairwise comparison test is used to determine which wells should be included in the characteristic well. The well with the largest average 
concentration and all other wells that are not significantly different (based on the TukeyKramer test at the 0.05 level) are included in the characteristic well with one constraint. At least one well with $50 \%$ or more of the results above detection must be included in the characteristic well if one exists. That is, if the largest concentration was the mean concentration from the wells with less than $50 \%$ above detection, then from among the wells with at least $50 \%$ above detection, the one with the largest average concentration must be included even if the F-ratio from the ANOVA and the TukeyKramer indicated significant differences at the 0.05 level.

\section{ESTIMATION OF AVERAGE CONCENTRATION}

Mean concentrations for the $\mathrm{POC}$ and $\mathrm{BG}$ wells are based on the analyses of the characteristic wells and are only computed if at least $10 \%$ of the results are above detection. $P O C$ versus $B G$ comparisons are also based on the comparison between the POC and BG characteristic wells and are computed only if at least one of the two wells has at least $50 \%$ of results above detection. The following steps describe the estimation process.

(1) If the characleristic well has at least $10 \%$ of the results above detection, the average of all quarter concentrations is computed.

(2) If the characleristic well has at least $50 \%$ of the results above detection, the variance and standard deviations are also computed.

(3) For the BG characteristic wells with at least $10 \%$ of the resulls above detection, the average is compared with the 90th percentile of all reported detection limits computed from the background wells. The larger of the 90th percentile of the detection limit and the well average is used in the $P O C$ versus $B G$ comparison.

\section{COMPARISON BETWEEN POC AND BG "CHARACTERISTIC" WELLS}

The null hypothesis being tested is

$H_{0}$ : The POC mean concentration is not greater than BG mean concentrations in the aquifer.

The alternate hypollhesis which is accepted if the null hypothesis is $r(e)$ en: led is

\author{
$\mathrm{H}_{\mathrm{a}}$ : The POC mean concentration is \\ greater than the $B G$ mean \\ concentration in the aquifer.
}

Let
$X(P O C) a i$ be the mean concentration for the ith constituent in aquifer-a for the POC characteristic well,

$X(B G)$ ai be the mean concentration for the ith constituent in aquifer-a for the $B G$ characteristic well,

DL90i be the 90th percentile detection limit for the ith constituent computed from the BG wells over all aquifers,

$S^{2}(P O C)_{a i}$ be the estimate of variance for the ith constituent in aquifer-a if the POC characteristic well has at least $50 \%$ of the quarters above detection; otherwise, the variance is undefined,

$S^{2}(B G)_{a i}$ be the estimate of variance for the ith constituent in aquifer-a if the BG characteristic well has at least $50 \%$ of the quarters above detection; otherwise, the variance is undefined,

$$
\begin{array}{ll}
n(P O C) a i & \begin{array}{l}
\text { be the number of quarters in } \\
\text { the POC characteristic well } \\
\text { for aquifer } a, \text { constituent } i, \\
\text { and }
\end{array} \\
n(B G) \text { ai } & \begin{array}{l}
\text { be the number of quarters in } \\
\text { the BG characteristic well } \\
\text { for aquifer } a, \text { constituent } i .
\end{array}
\end{array}
$$

No comparison test is done unless $X(P O C) a i>$ the maximum of (DL90; or $X(B G)$ ai). The following procedure describes the $P O C$ and $B G$ comparison methodology.

(1) At least $50 \%$ of the quarter means in the POC characteristic well are above detection for the constituent and aquifer, and 
(a) at least $50 \%$ of the quarter means in the BG characteristic well are above detection, the $B G$ mean is greater than $\mathrm{DL} 90_{i}$, and

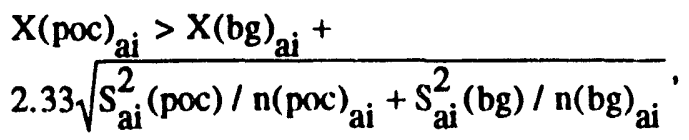

(b) or at least $10 \%$ and less than $50 \%$ of the quarter means in the BG characteristic well are above detection, the BG mean is greater than DL90i, and

$\mathrm{X}(\mathrm{poc})_{\mathrm{ai}}>\mathrm{X}(\mathrm{bg})_{\mathrm{ai}}+2.33 \sqrt{\mathrm{S}_{\mathrm{ai}}^{2}(\mathrm{poc}) / \mathrm{n}(\mathrm{poc})_{\mathrm{ai}}}$,

(c) or the BG characteristic well has fewer than $10 \%$ above detection, or the BG mean is less than the 90th percentile of the detection limit, and

$$
\mathrm{X}(\mathrm{poc})_{\mathrm{ai}}>D L 90_{\mathrm{i}}+2.33 \sqrt{\mathrm{S}_{\mathrm{ai}}^{2}(\mathrm{poc}) / \mathrm{n}(\mathrm{poc})_{\mathrm{ai}}}
$$

then the POC mean concentration is significantly greater than the BG concentration.

(2) At least $10 \%$ but less than $50 \%$ of the quarter means in the POC characteristic well are above detection, and

(a) at least $50 \%$ of the quarter means in the $B G$ characteristic well are ab $v \in$ cietection, the $B G$ mean is greater than $D L 90_{i}$, and

$X(p \circ)_{a i}>X(b g)_{a i}+$
$2.33 \sqrt{S_{a i}^{2}(b g) / n(p o c)_{a i}+S_{a i}^{2}(b g) / n(b g)_{a i}}$,

(b) or at least $50 \%$ of the quarter means in the BG characteristic well are above detection but the $B G$ mean is less than $D L 90_{j}$, and

$$
\mathrm{X}(\mathrm{poc})_{\mathrm{ai}}>D L 90_{\mathrm{i}}+2.33 \sqrt{\mathrm{S}_{\mathrm{ai}}^{2}(\mathrm{hg}) / \mathrm{n}(\mathrm{poc})_{\mathrm{ai}}} \text {. }
$$

then the POC mean concentration is significantly greater than the BG concentration.

(3) If the POC characteristic well has fewer than the $50 \%$ but at least $10 \%$ above detection, and the BG characteristic well has fewer than $50 \%$ above detection, no test comparison is done and the null hypothesis is not rejected. Both the POC and the BG means are computed.
(4) If fewer than $10 \%$ of the quarter means in the POC characteristic well are above detection, no comparison is made and the null hypothesis is not rejected.

\section{COMPARISON WITH OTHER METHODS}

Quarter results from 53 constituents were analyzed using the methodology described here. The $\mathrm{COC}$ list derived from the SRS analysis was compared with $\mathrm{COC}$ lists derived by two parametric and two non-parametric methods. The two parametric methods are Cohen's biased corrected maximum likelihood method and a regression of the normalized (Blom) ranks. Both the natural logarithm and unlogged quarter results were analyzed by the SRS and two parametric methods. The two non-parametric methods were Gehan and Wilcoxon two-sainple rank sum. The chosen constituents had at least $50 \%$ of the results above detection in the POC wells and at least 9 quarter results in both the $B G$ and POC characteristic wells.

The presence of multiple censoring limits complicates the comparisons for the parametric methods. A censoring limit (CL) equal to twice the largest quarter average less than detection was defined for each of the 53 constituents. All quarter results less than or equal to the $\mathrm{CL}$ were considr "ed to be "less than" regardless of whether it was originally less than detection or was based on a reported result. The $\mathrm{CL}$ generally equaled the previously defined 90 th percentile background detection limit.

Cohen's method is based on maximum likelihood estimates which are obtained by determining values for $\mu$ and $\sigma$ that maximize Eq. (1).

$$
\begin{aligned}
& \ln [\mathrm{L}(\mu, \sigma)]=-[(\mathrm{n}-\mathrm{k}) / 2] \ln \left(2 \pi \sigma^{2}\right)- \\
& {\left[\sum_{\mathrm{i}-\mathrm{k}+1}^{\mathrm{n}}\left(\mathrm{x}_{\mathrm{i}}-\mu\right)^{2} /\left(2 \sigma^{2}\right)\right]+\mathrm{k} \ln \Phi(\mathrm{x}<\mathrm{CL})^{\prime}}
\end{aligned}
$$

where $\mathrm{CL}$ is the censoring limit, $k$ is the number of results less than or equal to $\mathrm{CL}, \mathrm{n}$ is the total number of quarters, and $F(C L)$ is the cumulative normal distribution at $\mathrm{x}=\mathrm{CL}$.

The estimates of $\mu$ and $\sigma^{2}$ are given by

$$
\hat{\mu}=\overline{\mathrm{x}}_{\mathrm{n}-\mathrm{k}}-\hat{\sigma}\left(\frac{\mathrm{k}}{\mathrm{n}-\mathrm{k}}\right) \frac{\varphi(\mathrm{e})}{\Phi(\mathrm{e})} \text {, and }
$$




$$
\begin{aligned}
& \hat{\sigma}^{2}=\left[S_{n-k}^{2}+\left(\bar{x}_{n-k}-\hat{\mu}\right)^{2}\right] / \\
& {\left[1+\varepsilon\left(\frac{k}{n-k}\right) \frac{\varphi(\varepsilon)}{\Phi(\varepsilon)} l,\right.} \\
& \text { where } \bar{x}_{n-k}=\sum_{i=n-k}^{n} x_{i} /(n-k), \\
& S_{n-k}^{2}=\frac{\sum_{i=k+1}^{n}\left(x_{i}-\bar{x}_{n-k}\right)^{2}}{(n-k)},
\end{aligned}
$$

$\varphi(\varepsilon)$ is the normal probability density function,

$$
\text { and } \quad \varepsilon=\frac{(D L-\hat{\mu})}{\hat{\sigma}} .
$$

Cohen $(1959,1961)$ describes a procedure to minimize the bias of the above estimates.

(1) Compute the proportion less than $\mathrm{CL}$, $\mathrm{h}=\mathrm{k} / \mathrm{n}$.

(2) Compute the mean and variance of the $(n-k)$ measurements above the CL by

$$
\begin{aligned}
& \overline{\mathrm{x}}_{\mathrm{a}}=\frac{1}{(\mathrm{n}-\mathrm{k})} \sum_{\mathrm{i}=k+1}^{\mathrm{n}} \mathrm{y}_{\mathrm{i}} \text { and } \\
& \mathrm{s}_{\mathrm{a}}^{2}=\frac{1}{(\mathrm{n}-\mathrm{k})} \sum_{\mathrm{i}=k+1}^{\mathrm{n}}\left(\mathrm{x}_{\mathrm{i}}-\overline{\mathrm{x}}_{\mathrm{a}}\right)^{2} . \\
& \text { (3) Compute } \hat{\gamma}=\frac{\mathrm{s}_{\mathrm{a}}^{2}}{\left(\overline{\mathrm{x}}_{\mathrm{a}}-\mathrm{CL}\right)^{2}} .
\end{aligned}
$$

(4) Obtain an estimate of the parameter $\lambda$ from Table A15 in Gilbert (1987)]using linear interpolation if necessary and estimate the mean and variance by

$$
\begin{aligned}
& \hat{\mu}=\overline{\mathrm{x}}_{\mathrm{a}}-\hat{\lambda}\left(\overline{\mathrm{x}}_{\mathrm{a}}-\mathrm{CL}\right), \text { and } \\
& \hat{\sigma}_{x}^{2}=\mathrm{s}_{\mathrm{a}}^{2}+\hat{\lambda}\left(\overline{\mathrm{x}}_{\mathrm{a}}-\mathrm{CL}\right)^{2} .
\end{aligned}
$$

The regression method computes the Blom ranks for the quarter means using $S A S^{\circledR}$ PROC RANK (ref. 11) and then fits a linear regression with the original data as the dependent variable and the Blom ranks as the independent variable. The quarter results are ranked separately within the POC and BG characteristic well from smallest to largest. Tied values are given averaged ranks. Normal scores (Blom ranks) are computed from the ranks by

$$
y_{i}=F^{-1}\left[\left(r_{i}-3 / 8\right) /(n+1 / 4)\right]
$$

The results above the $C L$ are regressed on the Blom ranks as defined in eq. (13).

$$
x_{i}=\hat{a}+\hat{b} y_{i} \text {, }
$$

where $\hat{a}$ estimates the mean and $\hat{b}$ estimates the standard deviation.

The BG mean concentration was set equal to the larger of the 90th percentile detection limit or the estimated mean before making the POCBG comparison. Both Cohen's and the Blom rank regression estimates of mean concentration can be negative. When this occurred, the estimate was replaced by the 90th percentile detection limit. Cohen's method has another disadvantage in that the estimate of $\hat{\gamma}$ occasionally exceeds 1 and biased corrected estimates cannot be computed by the above method. This occurred for 13 of the 53 constituents using the unisyged data and once using the logged data.

The Wilcoxon two sample rank test was done after replacing the less than detection results with half the detection limit. Gehan does not require replacement of the less than detected results with any assur ed value. If the data are censored with only one tetection limit, the Wilcoxon Rank Sum Test is el uivalent to the Gehan method, which is discussec in Millard and Deveral (1988). The Gehan statistic is defined as follows: Let $m_{b}$ and $m_{s}$ denote the number of quarterly means in the BG and POC characteristic wells. Let $N=m_{b}+m_{s}$. Let $t_{1}<$ $t_{2}<\ldots<t_{k}$ denote the ordered distinct uncensored observations for the combined BG and POC characteristic wells for a given constituent and aquifer. For $i=1, \ldots, k$, let $d b i$ denote the number of quarter means from the $B G$ well that are equal to $t_{j}$, and $d_{s i}$ is similarly defined for the POC well. Set $d_{i}=d_{b i}+d_{s i}$. If there are no tied uncensored measurements, then di will always be equal to 1 . 
For averages less than detection, let $\mathrm{e}_{\mathrm{bi}}=$ the number of quarter means from the $B G$ well with censoring levels that fall into the interval $\left(t_{i}\right.$ $\left.1, t_{i}\right]$ where $t_{0}=-\infty$; $\theta_{s i}$ is similarly defined for the $P O C$ well. Let nLbi be the number of quarter results from the BG comparison well known to be less than or equal to $t_{j} ; n L s j$ is similarly defined for the POC well. Define $e_{j}=e_{b i}+e_{s i}$ and $n L i=n L b i+n L s i$. For the two-sample case, the score statistic can be written as

$$
v=\sum_{i=1}^{k}\left(d_{s i} C_{i}+e_{s i} C_{i}\right)
$$

where $C_{i}=n L i-(k-i+1)$ and $C_{i}=-(k-i+1)$. If the quarter means in the POC characteristic well are larger than those in the BG characteristic well, the statistic will be large. If ties occur among the uncensored data, then, as for the case of singly censored data, the average scores should be assigned to the tied measurements.

If the censoring mechanism is the same for the POC and BG wells, the permutation variance for the $v$ score is given by

$$
\operatorname{Var}_{p}=\left[m_{b} m_{S} / N(N-1)\right] \sum_{i=1}^{k}\left(d j c i^{2}+e i C_{i}^{2}\right) .
$$

The standardized Gehan statistic is $z=v / J V^{2} p$ with $p$ values computed from the standard normal distribution.

\section{RESULTS}

A total of 27 different COC's were identified by at least one of the six parametric method combinations (SRS, Blom regression, and Cohen's ML with both logged and unlogged data). These are broken down by method combinations in Tables 1 and 2. All $25 \mathrm{COC}$ 's based on the SRS-unlogged method were also identified by at least one other parametric method combination. All but one of the SRSlogged COC's (23) were identified by at least one other parametric method. The Gehan method identified $37 \mathrm{COC}$ 's and the Wilcoxon method identified 31. Gehan identified all 27 of the parametric COC's and Wilcoxon identified 26 out of the 27.
Estimates of the BG mean concentration exceeded the POC estimated mean concentration for two of the Gehan COC's. Gehan was the only method declaring these two constituents as COC's. The SRS method without the constraint of comparing to the larger of the BG mean or the 90th percentile detection limit, would have identified 4 additional COC's

\begin{tabular}{|c|c|c|c|c|}
\hline $\begin{array}{l}\text { Status } \\
\text { of } \\
\text { Data }\end{array}$ & SRS & $\begin{array}{l}\text { Blom } \\
\text { Rank } \\
\text { Reg. }\end{array}$ & $\begin{array}{l}\text { Cohen's } \\
\text { ML Gehan }\end{array}$ & $\begin{array}{l}\text { Wilcoxon } \\
\text { 2-sample }\end{array}$ \\
\hline $\begin{array}{l}\text { Unlogged } \\
\text { Logged }\end{array}$ & $\begin{array}{l}25 \\
24\end{array}$ & $\begin{array}{l}22 \\
23\end{array}$ & $\begin{array}{l}19^{*} \quad 37 \\
24^{* *}\end{array}$ & 31 \\
\hline
\end{tabular}
which were identified by both Gehan and Wilcoxon.

\section{Table 1: Number of COC's Identified by Each Method}

Common to both logged \& unlogged $\begin{array}{lll}22 & 20 & 18\end{array}$

* 13 constituents could not be tested.

**1 constituent could not be tested.

\section{Table 2: Breakdown of COC's by Multiple} Method Combinations

Method Combination

Number

of COC's

All 6 parametric methods 18 All except Cohen's-unlogged (could not be tested)

SRS \& Cohen's unlogged (tested)

SRS \& Regression-unlogged

Regression \& Cohen's-unlogged (tested)

All three parametric methods-logged

SRS \& Regression-logged

SRS \& Cohen's-logged

SRS-logged and Gehan, 0 unlogged

Wilcoxon \& at least one parametric method 26

Gehan \& Wilcoxon

Only Gehan

\section{CONCLUSIONS}

The advantages of the SRS method is that it is easy to implement using current statistical computing packages, it yields COC's that have practical (above 90th percentile detection limit) as well as statistical significance, and always yields estimates of mean concentration equal to 
or greater than the 90th percentile detection limit. Negative estimates of mean concentration can occur with both Cohen's and Blom rank regression methods. In addition, the POC-BG comparison cannot always be done with Cohen's method. Log transformation before analyzing the data is recommended when using Cohen's method if many of the constituents cannot be tested. The two non-parametric tests. Gehan and Wilcoxon, can include as COC's constituents that may have no practical difference. Gehan identified 2 COC's for which the BG mean concentration exceeded the POC mean concentration.

\section{REFERENCES}

[1] A. Clifford Cohen, Simplified Estimators for the Normal Distribution when Samples are Singly Censored or Truncated. Technometrics, 1,1959, pp 217-237.

[2] A. Clifford Cohen, Tables of Maximum Likelihood Estimates: Singly Truncated and Singly Censored Samples. Technometrics, 3: 1961, pp. 535-541.

[3] A. Clifford Cohen, Progressively Censored Sampling in the Three Parameter LogNormal Distribution, Technometrics, 18, 1976 pp 99-103.

[4] Richard O. Gilbert, Statistical Methods for Environmental Pollution Monitoring, Van Nostrand Reinhold, New York, 1987.

[5] Dennis R. Helsel and Timothy A. Cohn, Estimation of Descriptive Statistics for Multiply Censored Water Quality Data, Water Resources Research, 24, 12,1988, pp. 1997-2004

[6] Robert B. Latla, A Monte Carlo Study of Some Two-Sample Rank Tests with Censored Data, JASA, 76, 375, (1981), pp. 713-719.

[7] Steven P. Millard and Steven J. Deverel, Nonparametric Statistical Methods for Comparing Two Sites Based on Data with Multiple Nondetect Limits, Water Resources Research, 24,1988, pp. 2087-2098.

[8] Michael C. Newman, Philip M. Dixon, Brian B. Looney, \& John E. Pinder, III,

Estimating Mean and Variance for Environmental Samples with Below Detection Limit Observations, Water Resources Bulletin, 25, 1989, pp. 905-916.

[9] R. L. Prentice, Linear Rank Tests with Right Censored Data Biometrika, 65, 1978, pp. 57-179.

[10] R. L. Prentice and P. Marek, A Qualitative Discrepancy between Censored Data Rank Tests, Biometrics 35, 1979, pp 861-867.

[11] SAS@Procedures Guide, Version 6, 3rd Edition, SAS Institute Inc., Cary, NC (1990). 

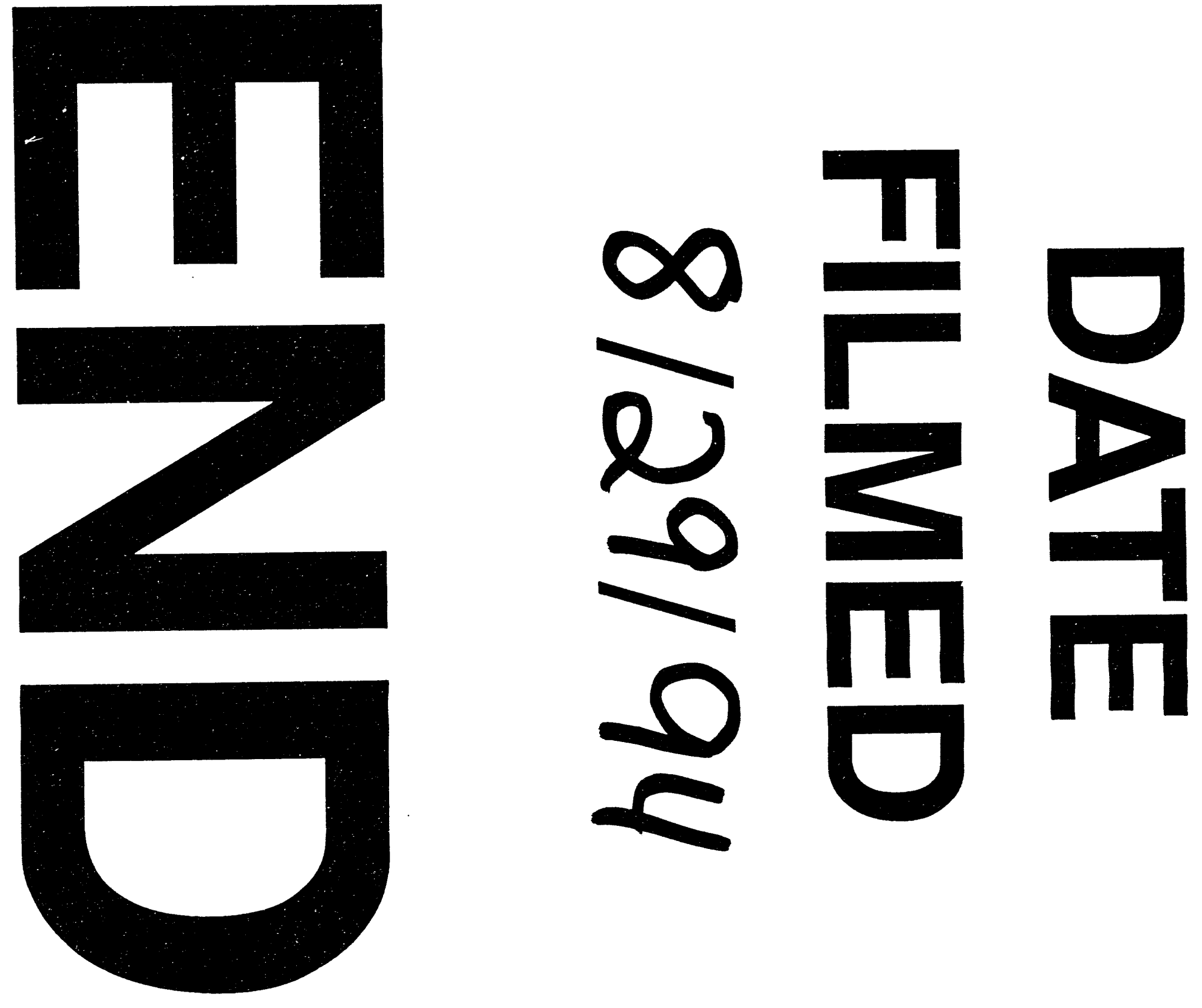
